\title{
Immobilization of Lipase CALB in Organically Modified Silica
}

\author{
Aline Matuella Moreira Ficanha 1,2 ${ }^{\mathbb{D}}$, Angela Antunes ${ }^{2} \mathbb{D}$, Carolina Elisa Demaman Oro ${ }^{2} \mathbb{D}$, Elton \\ Franceschi $^{3}$ (D), Rogério Marcos Dallago 2 (D), Marcelo Luis Mignoni 2,*(D) \\ 1 Department of Engineering, Centro de Ensino Riograndense, CEP 99150000 Marau - RS, Brazil; \\ alinematuella@gmail.com (A.M.M.F.); \\ 2 Department of Food and Chemical Engineering, URI - Erechim, 1621, Sete de Setembro Av., Erechim - RS, 99709-910, \\ Brazil; nenaantunes@gmail.com (A.A.); carolinae.oro@hotmail.com (C.E.D.O.); dallago@uricer.edu.br (R.M.D.); \\ mignoni@uricer.edu.br (M.L.M.); \\ 3 Center for Studies on Colloidal Systems (NUESC)/Institute of Technology and Research (ITP), Postgraduate Programme \\ in Industrial Biotechnology (PBI), Tiradentes University (UNIT), Av. Murilo Dantas, 300, Aracaju, SE CEP 49032-490, \\ Brazil; franceschi.elton@gmail.com (E.F.); \\ * Correspondence: mignoni@uricer.edu.br;
}

Received: 7.06.2020; Revised: 1.07.2020; Accepted: 2.07.2020; Published: 4.07.2020

Abstract: In order to improve the activity of enzymes immobilized in silica, additives such as polyethylene glycol (PEG) can be introduced in the sol-gel process. This addition aims to protect the enzymes from denaturing effects by forming protection between the protein and the reaction medium. Thus, the aim of the work was to evaluate the effect of the use of the PEG additive in the process of immobilization of the commercial lipase of Candida antarctica B (CALB) in xerogel and aerogel obtained by the sol-gel technique. The mathematical model for the process was validated, and the optimum points determined were $0.09 \mathrm{~g} / \mathrm{ml}$ of enzyme and $0.15 \mathrm{~g} / \mathrm{ml}$ of polyethylene glycol additive for the xerogel and $0.12 \mathrm{~g} / \mathrm{ml}$ of enzyme and $0.20 \mathrm{~g} / \mathrm{mL}$ of polyethylene glycol additive for the aerogel. The maximum esterification activity and yield values were $544 \mathrm{U} / \mathrm{g}, 585 \%$, and $266 \mathrm{U} / \mathrm{g}, 140 \%$ for xerogel and aerogel, respectively. Polyethylene glycol showed better performance in the esterification activity and stability as an additive when used in the xerogel, that is, when the process of obtaining the support uses the removal of the solvent only by evaporation. Regarding aerogel, a reduction in enzyme activity was observed, which may be due to the interaction of PEG with $\mathrm{CO}_{2}$ in the drying process.

Keywords: aerogel; xerogel; sol-gel; CALB; stability.

(C) 2020 by the authors. This article is an open-access article distributed under the terms and conditions of the Creative Commons Attribution (CC BY) license (https://creativecommons.org/licenses/by/4.0/).

\section{Introduction}

Among the different supports used for enzymatic immobilization, the sol-gel process is gaining attention, as silica-based materials produced by the sol-gel technique are characterized by effective thermal resilience, high-pressure resistance, low density, high porosity, high specific surface area, low thermal conductivity, and also high resistance to aggressive media [1-3]. Silica aerogels and xerogels are particularly interesting because they can be employed to design relatively strong recyclable biocatalysts. Furthermore, their pore surface can be functionalized with a large range of organic groups to be chosen for the best activity of a given enzyme [4]. The functionalization of silica-based matrices can further enhance the enzyme microenvironment, contributing to the concern of catalytic activity and to selectivity and specificity [1], during biotechnological processes. It also allows the reuse of the enzyme over 
an extended period of time and easier separation of catalysts and products. Thus, lipases are interesting enzymes because they catalyze important reactions, such as hydrolysis, interesterification, esterification, aminolysis, and alcoholysis regarding triglycerides and fatty acids of oils and fats [5, 6]. Lipase B from Candida antarctica (CALB) was selected due to its stability and commercial accessibility [7].

The organic groups, such as poly(ethylene glycol) (PEG), in the oxide network, give structural flexibility by reducing the degree of cross-linking and lead to a change in the threedimensional gel network because of several reasons [8]. PEG is a hydrophilic polymer, nonionic, water-soluble, and has properties such as easy control, thermosensitivity, biodegradability, and biocompatibility [9]. In this sense, the properties of inorganic and organic compounds are incorporated into one material, called organically modified silica (ORMOSILs) [8].

The drying process of the sol-gel technique aims to remove the solvent from the gel, and it plays an important role in the sol-gel method of obtaining polymer composite materials. Depending on the methods used, it is possible to obtain different synthesized products (films, hydrogels, cryogels, xerogels, and aerogels) [10].

Recently, the use of sol-gel-based immobilization routes has gained a lot of attention [11]. In this sense, the aim of this work was to evaluate the effect of PEG as an additive in the process of immobilization of the commercial lipase of Candida antarctica B (CALB) in xerogel and aerogel obtained by the sol-gel technique.

\section{Materials and Methods}

\subsection{Materials.}

The commercial lipase from Candida antarctica (CALB) was obtained from Novozyme (Bagswaerd, Denmark). The chemicals used for the sol-gel synthesis were tetraethoxysilane (TEOS Sigma-Aldrich) as a silica precursor, ammonium hydroxide (Quimex), hydrobromic acid (Vetec) as a catalyst, polyethylene glycol (PEG 1500) (Merck) as a stabilizing agent (additive), and distilled water. To determination of esterification activity were used: ethanol (Merck), acetone (Merck), and sodium hydroxide (Synth). The substrate used in the esterification reaction was oleic acid (Aldrich) and ethanol (Merck). Carbon Dioxide $\left(\mathrm{CO}_{2}\right)$ (White Martins) was used for the drying of the support to obtain aerogel as a solvent.

\subsection{Synthesis of silica and CALB lipase immobilization in xerogel and aerogel.}

The Candida antarctica $B$ lipase was immobilized by the sol-gel technique, with the use of tetraethylorthosilicate (TEOS) as a precursor of silica, according to a methodology previously established [12]. Initially, $5 \mathrm{ml}$ of TEOS were dissolved in $5 \mathrm{ml}$ of absolute ethanol. After dissolution, $1.6 \mathrm{ml}$ of distilled water and three drops of the initiator of the polymerization reaction, hydrobromic acid $(\mathrm{HBr})$, were added. Subsequently, the reaction systems were subjected to an orbital shaker at $40^{\circ} \mathrm{C}, 180 \mathrm{rpm}$, for a period of $90 \mathrm{~min}$. Then, $1 \mathrm{ml}$ of the solution of the PEG additive and the enzymatic solution was added and, finally, $1.75 \mathrm{ml}$ of the hydrolyzing solution (1.0 mol / L ethanolic ammonium hydroxide solution) was added. Subsequently, the reaction systems were maintained in static conditions at a temperature between $20^{\circ} \mathrm{C}$ and $25^{\circ} \mathrm{C}$ for $24 \mathrm{~h}$ to complete the chemical condensation. 
To obtain the xerogel, after $24 \mathrm{~h}$, the support was placed in a vacuum desiccator (room temperature) for a period of $24 \mathrm{~h}$ to complete the drying by evaporation. After drying in mild conditions of temperature and pressure, lipase immobilized on silica, called immobilized xerogel, was obtained.

To obtain the aerogel, after $24 \mathrm{~h}$ of chemical condensation, the support was subjected to pressure conditions of $80 \mathrm{bar}$, the temperature of $40^{\circ} \mathrm{C}$ for a time of $30 \mathrm{~min}$ as described by Ficanha et al. [13], to complete drying by solvent extraction. After drying in supercritical $\mathrm{CO}_{2}$ conditions, the lipase immobilized on silica, called immobilized aerogel, was obtained.

2.3. Influence of the enzyme mass and PEG additive on the immobilization of the CALB lipase in xerogel and aerogel.

The values of the variables used to assess the influence of different concentrations of enzyme and additive in the immobilization stage were based on studies previously carried out [12]. First, the enzyme concentration was fixed at $0.10 \mathrm{~g} / \mathrm{mL}$, and the concentration of the additive was varied from 0.05 to $0.3 \mathrm{~g} / \mathrm{mL}$. Likewise, tests were carried out to assess the influence of the enzyme in the xerogel technique: the concentration of the additive was fixed at $0.05 \mathrm{~g} / \mathrm{mL}$, and the enzyme concentrations were varied $(0.05-0.2 \mathrm{~g} / \mathrm{mL})$.

From the results obtained in the preliminary tests, a complete Rotational Central Compound Design (DCCR) $2^{2}$ was proposed to optimize the studied variables and obtain maximum esterification activity in the immobilized xerogel and aerogel. The values of the variables used in the DCCR are shown in Table 1.

Table 1. Real and coded variables tested in the Complete Rotational Central Compound Design (DCCR) $2^{2}$ in the immobilization of the CALB lipase in xerogel and aerogel.

\begin{tabular}{l|l|l|l|l|l}
\multirow{2}{*}{ Variáveis } & \multicolumn{5}{l}{ Níveis } \\
\cline { 2 - 6 } & -1.41 & -1 & 0 & 1 & 1.41 \\
\hline $\mathbf{X}_{\mathbf{1}}$ & 0.029 & 0.05 & 0.10 & 0.15 & 0.170 \\
\hline $\mathbf{X}_{\mathbf{2}}$ & 0.059 & 0.10 & 0.20 & 0.30 & 0.341 \\
$\mathrm{X}_{1}$ : enzyme $(\mathrm{g} / \mathrm{mL}) ; \mathrm{X}_{2}$ : additive $(\mathrm{g} / \mathrm{mL})$.
\end{tabular}

The optimal levels of enzyme and additive were confirmed by triplicate experiments performed under the optimal conditions described by the statistical model. After confirmation, tests of operational stability and storage of optimized xerogels and aerogels were carried out.

The statistical analysis related to the estimation of the effects of each of the variables was performed using pure error and the relative standard deviation between experimental and predicted data, which were performed considering a 95\% confidence level $(p<0.05)$ using Statistica 5 software.

\subsection{Analytical determinations.}

2.4.1. Determination of esterification activity.

The esterification activity (EA) of the immobilized enzyme was carried out by the synthesis reaction of oleic acid and ethanol (molar ratio 1:1), according to Ficanha et al. [13].

\subsubsection{Determination of immobilization yield.}

The immobilization yield in the supports was calculated by the percentage of the ratio between the total esterification activity of the immobilized support and the total esterification 
activity of the free enzyme mass added in the immobilization step, according to Equation 1, where the yield is the ratio between the total esterification activity of the support mass $\left(U_{x}\right)$ and the total esterification activity present in the free enzyme mass added to the immobilization $\left(\mathrm{U}_{0}\right)$, as described by [12].

$$
\text { Yield }(\%)=\frac{U_{x}}{U_{0}} \times 100
$$

\subsubsection{Storage stability.}

Storage stability is an important parameter that must be evaluated since its study will allow us to determine how long the immobilized biocatalyst can be stored and how much of its initial activity will be maintained throughout the storage period. The experiments were carried out at refrigeration temperature (between $3{ }^{\circ} \mathrm{C}$ and $5^{\circ} \mathrm{C}$ ) for a period of 350 days. The stability was monitored until reaching a loss of $50 \%$ of its initial esterification activity. The results were presented as a percentage of residual activity (RA), calculated by Equation 2 .

$$
R A(\%)=\frac{E A_{i}}{E A_{0}} \times 100
$$

Where: $\mathrm{EA}_{\mathrm{i}}=$ esterification activity at time " $i$ "; $\mathrm{EA}_{0}=$ initial esterification activity.

\subsubsection{Operational stability.}

The efficiency of the operational stability (reuse) of the lipase immobilized in xerogel and aerogel was determined using a defined amount of the immobilized in successive cycles of ethyl oleate synthesis. After each batch, the reaction medium (liquid phase) was removed, and the solid phase (immobilized xerogel or aerogel) was maintained. After this step, a new solution of oleic acid and ethanol was added. The residual activity of each cycle was calculated by the ratio of esterification activity in cycle $n$ to the esterification activity in cycle 1 (initial activity).

\subsubsection{Thermal stability.}

The thermal stability of immobilized CALB lipase was determined by the Arrhenius method. From the data obtained during the thermal stability evaluation, the degradation kinetics was determined through the analysis of the reaction order. For this, the experiment was carried out by incubating the enzymes at temperatures from $40{ }^{\circ} \mathrm{C}$ to $80{ }^{\circ} \mathrm{C}$. Samples were taken over the incubation time to perform the esterification activity and to determine the residual activity. The thermal deactivation constant $\left(\mathrm{k}_{\mathrm{d}}\right)$ at each temperature was calculated according to the Arrhenius kinetic model, considering that the enzyme deactivation follows the first-order kinetics, according to Equation 3.

$$
A=A_{0} \exp \cdot\left(-k_{d} \cdot t\right)
$$

Where: $\mathrm{A}=$ final activity; $\mathrm{A} 0=$ initial activity; $\mathrm{t}=$ time.

From the thermal deactivation constants at each temperature, the half-life times $\left(t_{1 / 2}\right)$ (Equation 4) were obtained, which corresponds to the time necessary for the inactivation of $50 \%$ of the initial enzyme concentration to occur at the temperature tested.

$$
t_{1 / 2}=-\frac{\ln 0,5}{k_{d}}
$$

Where: $\mathrm{t}_{1 / 2}=$ half-life time; $\mathrm{k}_{\mathrm{d}}=$ deactivation constant. 


\section{Results and Discussion}

\subsection{Influence of enzyme and additive mass on esterification activity.}

Figure 1 shows the esterification activity and yield obtained in the preliminary tests for the influence of enzyme and additive mass on esterification activity in the immobilization of the CALB lipase in xerogel.

For the variation of the additive concentration with the enzyme concentration fixed at $0.10 \mathrm{~g} / \mathrm{mL}$, as can be seen in Figure 1a, a positive effect of the additive is observed, providing an increase in the esterification activity of approximately $400 \mathrm{U} / \mathrm{g}$ (observed for 0.05 and 0.1 $\mathrm{g} / \mathrm{mL}$ ) to approximately $800 \mathrm{U} / \mathrm{g}$, (observed for 0.20 and $0.30 \mathrm{~g} / \mathrm{mL}$ ). The same tendency is observed for the yield response, which was already expected due to the fact that it considers the initial activity offered in its calculations, which was the same in all tests. Starting from the same activity offered, the yield tends to vary proportionally with the esterification activity.

The positive effect observed for the use of the PEG additive in the immobilization process is similar to that reported in the literature. It was linked to a better distribution of the enzyme on the support surface, and to the fact that PEG affects the moisture level, provided by modification of the hydrophobicity of the microenvironment. This favors the contact of the immobilized enzyme with the reaction medium; therefore, the reaction conditions [14].
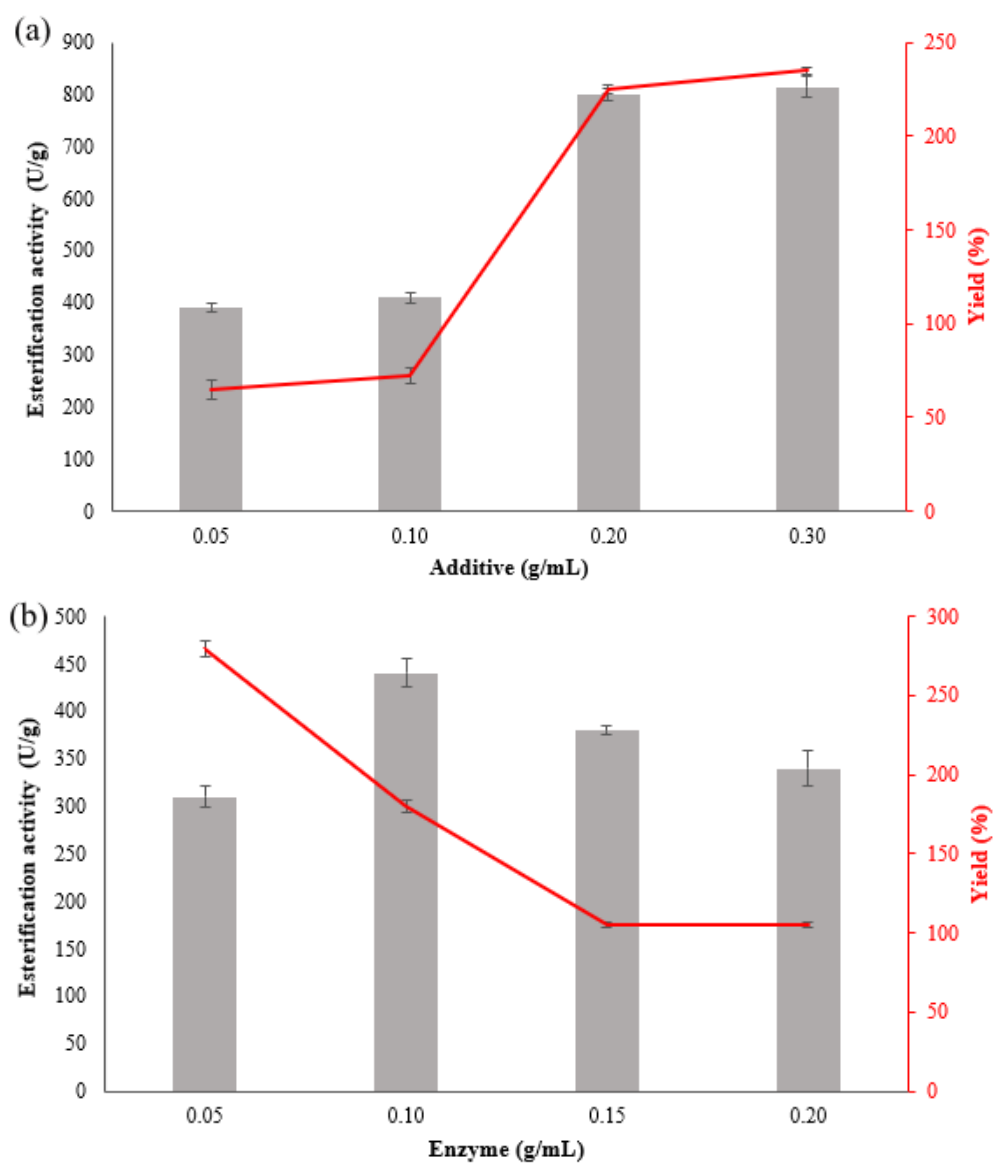

Figure 1. Esterification activity (columns) and yield (lines) obtained in preliminary tests for CALB lipase immobilized in xerogel. (a) The concentration of the enzyme fixed at $0.10 \mathrm{~g} / \mathrm{mL}$, and (b) concentration of additive fixed at $0.05 \mathrm{~g} / \mathrm{mL}$. 
In addition, the use of the additive can also influence the pore morphology of the gel, thereby facilitating the transfer of internal mass and providing greater accessibility of the substrate [15]. This consideration is in agreement with the results obtained in this study.

For the variation of the enzyme concentration (Figure 1b), when the concentration of the additive was fixed $(0.05 \mathrm{~g} / \mathrm{mL})$ the behavior changes, they are showing an increase in the esterification activity when the concentration of the enzyme exceeds 0.05 (approximately 300 $\mathrm{U} / \mathrm{g}$ ) to $0.10 \mathrm{~g} / \mathrm{mL}$ (approximately $450 \mathrm{U} / \mathrm{g}$ ), followed by a continuous decrease in esterification activity until the highest concentration of enzyme tested $(0.20 \mathrm{~g} / \mathrm{mL})$. Regarding the yield, a negative effect is observed with the enzyme concentration. This tendency indicates that the increase in the activity was not proportional to the increase in the initial activity offered, linked to the mass of enzyme used in the tests.

To confirm the preliminary results, a complete DCCR $2^{2}$ was performed in order to optimize the immobilization process and obtain maximum esterification activity. DCCR was performed for lipase immobilized in xerogel and aerogel. Tables 2 and 3 show the experimental matrix and the results obtained for the esterification activity for the different variables and levels studied in the DCCR.

Table 2. Experimental DCCR $2^{2}$ matrix for the esterification activity (EA) of lipase immobilized in xerogel at

\begin{tabular}{l|c|c|c|c|c|c} 
Treatments & $\begin{array}{c}\text { Enzyme } \\
(\mathbf{g} / \mathbf{m L})\end{array}$ & Additive $(\mathbf{g} / \mathbf{m L})$ & $\begin{array}{c}\text { Xerogel } \\
\text { mass }(\mathbf{g})\end{array}$ & $\mathbf{E A}(\mathbf{U} / \mathbf{g}) \pm \mathbf{\sigma}$ & $\begin{array}{c}\text { EA } \\
\text { Predicted } \\
(\mathbf{U} / \mathbf{g})\end{array}$ & $\begin{array}{c}\text { Relative } \\
\text { deviation } \\
(\mathbf{\%})\end{array}$ \\
\hline 1 & $-1(0.05)$ & $-1(0.10)$ & 6.48 & $463.40 \pm 17.84$ & 411.48 & 11.20 \\
\hline 2 & $+1(0.15)$ & $-1(0.10)$ & 7.00 & $424.76 \pm 12.14$ & 365.74 & 13.90 \\
\hline 3 & $-1(0.05)$ & $+1(0.30)$ & 7.58 & $338.05 \pm 13.62$ & 339.99 & -0.57 \\
\hline 4 & $+1(0.15)$ & $+1(0.30)$ & 7.88 & $70.09 \pm 11.68$ & 64.93 & 7.37 \\
\hline 5 & $-1.41(0.029)$ & $0(0.20)$ & 7.13 & $319.58 \pm 7.01$ & 343.25 & -7.41 \\
\hline 6 & $+1.41(0.170)$ & $0(0.20)$ & 8.16 & $83.33 \pm 11.90$ & 117.08 & -40.50 \\
\hline 7 & $0(0.10)$ & $-1.41(0.059)$ & 6.94 & $428.13 \pm 6.62$ & 495.04 & -15.63 \\
\hline 9 & $0(0.10)$ & $+1.41(0.341)$ & 8.88 & $242.06 \pm 18.18$ & 232.58 & 3.92 \\
\hline 10 & $0(0.10)$ & $0(0.20)$ & 7.83 & $538.52 \pm 18.01$ & 540.07 & -0.29 \\
\hline 11 & $0(0.10)$ & $0(0.20)$ & 7.90 & $533.49 \pm 17.84$ & 540.07 & -1.23 \\
\hline
\end{tabular}

Table 3. Experimental DCCR $2^{2}$ matrix for the esterification activity (EA) of lipase immobilized in aerogel at

\begin{tabular}{|c|c|c|c|c|c|c|}
\hline Treatments & $\begin{array}{l}\text { Enzyme } \\
(\mathrm{g} / \mathrm{mL})\end{array}$ & $\begin{array}{l}\text { Additive } \\
\text { (g/mL) }\end{array}$ & $\begin{array}{l}\text { Aerogel } \\
\text { mass (g) }\end{array}$ & $\mathbf{E A}(\mathbf{U} / \mathbf{g}) \pm \boldsymbol{\sigma}$ & $\begin{array}{l}\text { EA } \\
\text { Predicted } \\
\text { (U/g) }\end{array}$ & $\begin{array}{l}\text { Relative } \\
\text { deviation } \\
(\%)\end{array}$ \\
\hline 1 & $-1(0.05)$ & $-1(0.10)$ & 3.60 & $35.82 \pm 16.97$ & 21.36 & 40.35 \\
\hline 2 & $+1(0.15)$ & $-1(0.10)$ & 4.33 & $202.96 \pm 5.91$ & 171.24 & 15.63 \\
\hline 3 & $-1(0.05)$ & $+1(0.30)$ & 3.68 & $89.74 \pm 5.49$ & 93.71 & -4.42 \\
\hline 4 & $+1(0.15)$ & $+1(0.30)$ & 4.70 & $161.74 \pm 23.67$ & 148.44 & 8.22 \\
\hline 5 & $-1.41(0.029)$ & $0(0.20)$ & 4.64 & $63.30 \pm 18.13$ & 65.02 & -2.71 \\
\hline 6 & $+1.41(0.17)$ & $0(0.20)$ & 4.88 & $183.07 \pm 15.80$ & 209.27 & -14.31 \\
\hline 7 & $0(0.10)$ & $-1.41(0.059)$ & 4.02 & $37.40 \pm 5.79$ & 64.42 & -72.24 \\
\hline 8 & $0(0.10)$ & $+1.41(0.341)$ & 4.90 & $98.46 \pm 9.79$ & 99.35 & -0.91 \\
\hline 9 & $0(0.10)$ & $0(0.20)$ & 3.97 & $249.27 \pm 33.76$ & 247.40 & 0.75 \\
\hline 10 & $0(0.10)$ & $0(0.20)$ & 4.01 & $249.76 \pm 6.65$ & 247.40 & 0.94 \\
\hline 11 & $0(0.10)$ & $0(0.20)$ & 4.03 & $243.51 \pm 24.93$ & 247.40 & -1.60 \\
\hline
\end{tabular}

Tables 2 and 3 show that, for both xerogel and aerogel, the greatest esterification activities were obtained at the central point, using a concentration of $0.10 \mathrm{~g} / \mathrm{ml}$ of enzyme and $0.20 \mathrm{~g} / \mathrm{ml}$ of additive.

When comparing the results of the central point, a reduction of approximately $50 \%$ in the $\mathrm{AE}$ value for aerogel $(247.5 \pm 3.5 \mathrm{U} / \mathrm{g})$ is observed in relation to the xerogel $(540.3 \pm 7.8$ 
$\mathrm{U} / \mathrm{g}$ ). This result may be due to the removal of PEG, together with solvents, in the drying step in a pressurized medium with $\mathrm{CO}_{2}$ [16]. PEG has a high solubility due to the specific interactions between $\mathrm{CO}_{2}$ and the functional groups of the polymer, which favor solubility. This is in accordance with the lower mass presented by the aerogels in relation to their corresponding xerogels, as can be seen in Tables 2 and 3.

The model was validated by analysis of variance (ANOVA) showing a good performance in the F-test, in which the calculated $F$ values of 21.93 and 24.25 are higher than the F tabulated (5.05), for the xerogel and aerogel, respectively. The model was validated with 95\% confidence. Thus, the variables were significant, with an $\mathrm{R}^{2}$ of 0.95 and 0.96 for the xerogel and aerogel, respectively. This suggests a satisfactory representation of the immobilization process, with the response surface and contour curve shown in Figure 2.

(a)
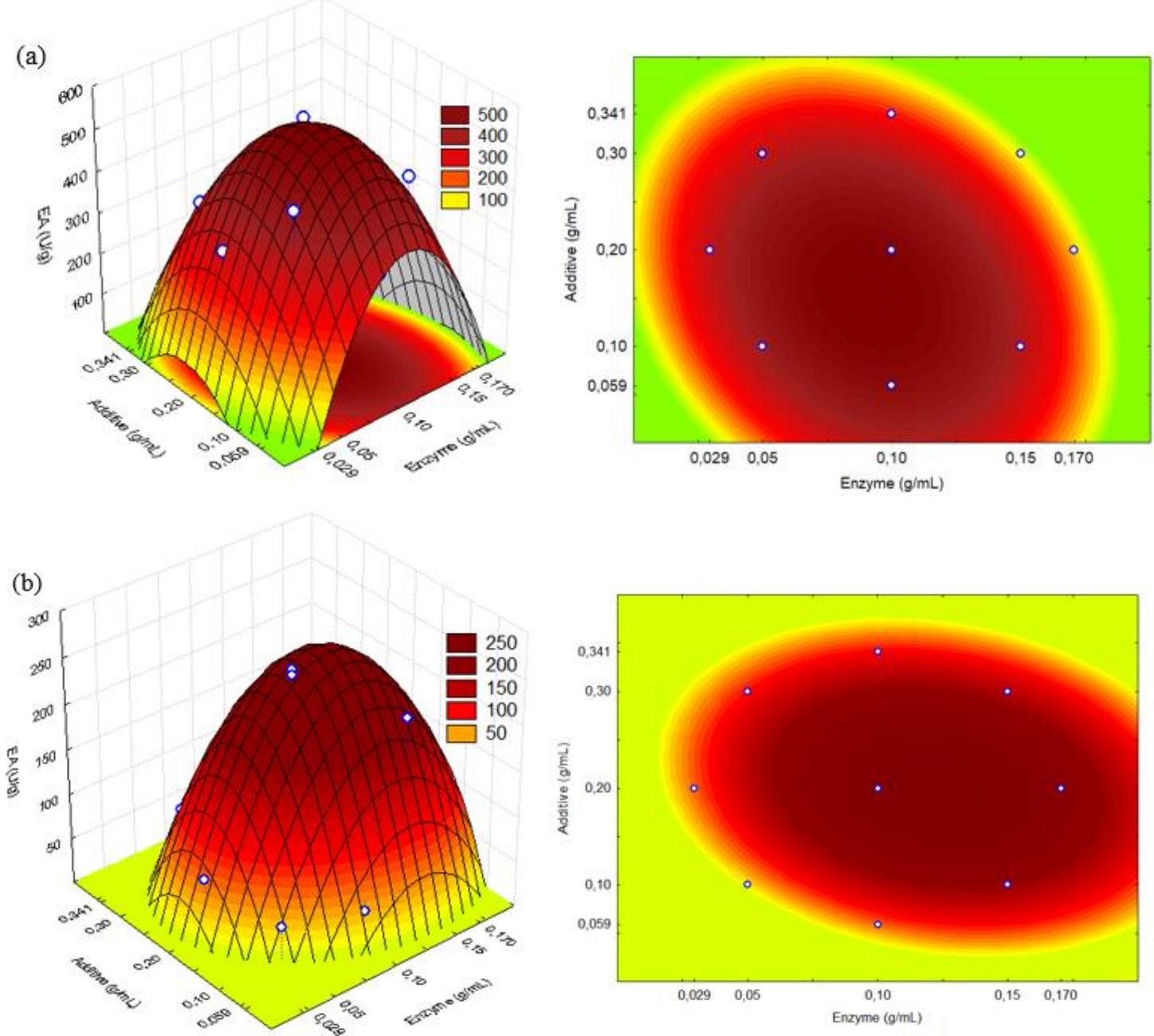

Figure 2. Response surface and contour curve of the influence of enzyme and additive (PEG) concentration on immobilization in (a) xerogel and (b) aerogel.

In addition, empirical models were obtained as a function of the enzyme and additive concentration for xerogels (Equation 5) and aerogels (Equation 6), which were used to calculate the predicted activity and relative deviation between the actual and the predicted result by the model (shown in Tables 2 and 3). Equations 5 and 6 are predictive of esterification activity (xerogels and aerogels, respectively) for the factors studied. It consists of a second-order function of the enzyme concentration $\left(\mathrm{X}_{1}\right)$ and additive concentration $\left(\mathrm{X}_{2}\right)$. 
EA $(U / g)$ xerogel $=540.07-80.20 X_{1}-155.88 X_{1}^{2}-93.07 X_{2}-88.66 X_{2}^{2}-57.33 X_{1} X_{2}$

$\mathrm{EA}(U / g)$ aerogel $=247.40+51.15 X_{1}-55.46 X_{1}^{2}+12.39 X_{2}-83.25 X_{2}^{2}-23.79 X_{1} X_{2}$

For further validation of the model, the concentration of enzyme and optimal additives were calculated by equalizing the first derivative of the esterification activity as a function of the enzyme and the additive equal to zero in both mathematical models.

The maximum esterification activities of lipases immobilized in xerogel were obtained at levels -0.17 and -0.47 for enzyme and additive, respectively, corresponding to $0.09 \mathrm{~g} / \mathrm{ml}$ of the enzyme concentration and $0.15 \mathrm{~g} / \mathrm{ml}$ of PEG. For CALB lipase immobilized in aerogel, the maximum esterification activities were obtained at levels +0.46 and +0.008 for enzyme and additive, respectively, corresponding to enzyme concentration of $0.12 \mathrm{~g} / \mathrm{mL}$ and $0.20 \mathrm{~g} / \mathrm{ml}$ of PEG.

\subsection{Validation of the experimental model.}

The validations were performed in triplicate under the optimal conditions, as described by the statistical model, to confirm the levels of enzyme and additive concentration to obtain maximum esterification activity. The results are shown in Table 4.

Table 4. Validation of the optimized variables described by the mathematical model.

\begin{tabular}{l|l|l|l|l|l|l} 
Support & Enzyme (g) & Additive (g) & EA (U/g) $\pm \boldsymbol{\sigma}$ & EA Predicted (U/g) & Relative deviation (\%) & Yield (\%) \\
\hline Xerogel & 0.09 & 0.15 & $543.65 \pm 18.18$ & 568.78 & -4.62 & 585 \\
\hline Aerogel & 0.12 & 0.20 & $265.63 \pm 11.72$ & 259.20 & 2.42 & 140
\end{tabular}

According to Table 4, the relative deviation for xerogel immobilization was $-4.62 \%$, and for aerogel was $2.42 \%$. In addition, yields above $100 \%$ are observed, with the xerogel showing higher immobilization yield (585\%). The results demonstrate that the model obtained is adequate to explain the immobilization process and can predict the values of esterification activity.

\subsection{Storage stability.}

Figure 3 shows the residual activity for xerogels and aerogels stored in refrigeration (between $3{ }^{\circ} \mathrm{C}$ and $5{ }^{\circ} \mathrm{C}$ ) for a period of 350 days.

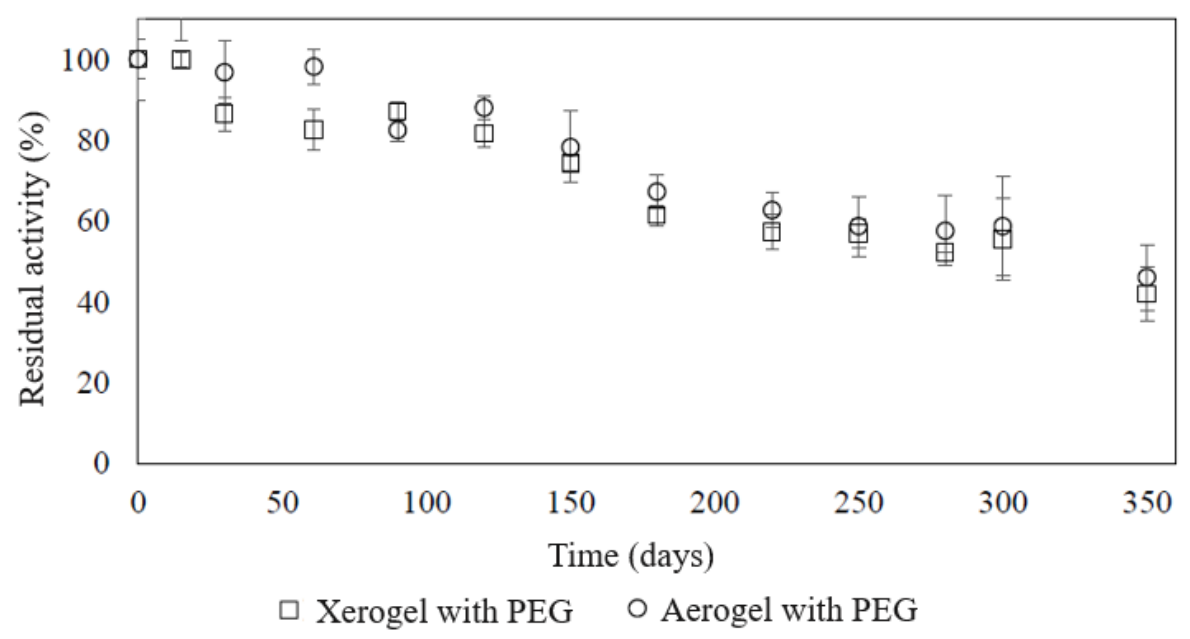

Figure 3. Residual activity in refrigeration storage stability of CALB immobilized on silica xerogel and aerogel. 
For storage stability in refrigeration, the two supports showed similar behavior. After 300 days of storage, both supports (xerogel and aerogel) synthesized using PEG as an additive showed an RA higher than 50\%. Lipases are usually immobilized onto/inside solid materials to enhance their activity, stability, and reusability. However, the results obtained for the immobilized enzymes depend on the supports employed, as they can change the microenvironment around an immobilized enzyme and affect the enzyme activity as well as stability [17].

\subsection{Operational stability.}

The operational stability of xerogels and aerogels using PEG as an additive was verified in esterification reactions in consecutive batches with the reuse of the support. The results obtained for operational stability can be seen in Figure 4.

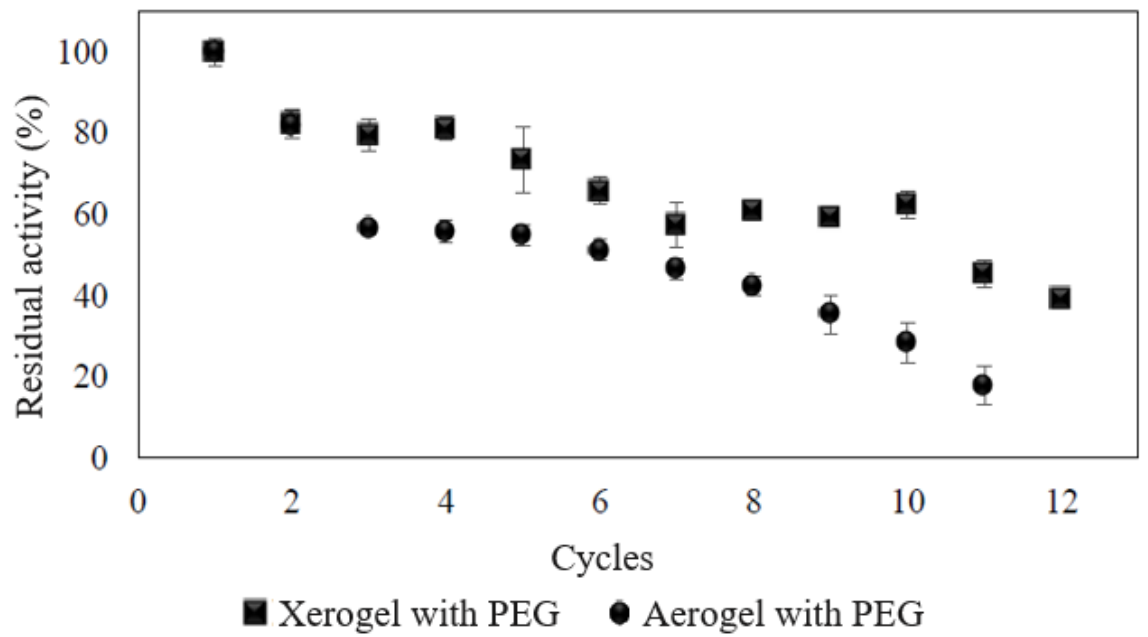

Figure 4. Operational stability of CALB immobilized on silica xerogel and aerogel using PEG as an additive.

A reduction in RA was observed due to the number of reuses for both supports. When comparing the xerogel with the aerogel, the possibility of using the xerogel for more cycles is observed, since the xerogel presented an AR of $65 \%$ in the 10th cycle. In addition, the xerogel presented 4 cycles more than the aerogel, which presented an AR of $51 \%$ in 6 cycles.

This behavior can be related to the form of drying in which the supports were submitted. In the aerogel, some of the PEG additives may have been removed together with the solvents at the time of drying, and this facilitates the leaching of the enzyme from the support when using it in a continuous process such as recycling. In the case of the xerogel, the higher concentration of PEG present in the immobilized material may be hindering the enzyme leaching. In this sense, the process conditions have a significant effect on the immobilized enzyme [18].

The results obtained for the stability, both for storage and for operational, are similar to those found in the literature for supports obtained via sol-gel [12]. It is important to study the stability after several reaction cycles to minimize decreasing of catalytic activity and develop a feasible enzymatic process for industrial applications [19] and reduce costs by reusing them in comparison to enzyme soluble form [20]. 


\subsection{Thermal stability.}

Thermal stability was assessed by calculating the thermal deactivation constant $\left(\mathrm{k}_{\mathrm{d}}\right)$ and half-life $\left(\mathrm{t}_{1 / 2}\right)$ of the CALB lipase immobilized in xerogel and aerogel with and without the presence of the PEG additive (Table 5).

Table 5. Thermal deactivation constant $\left(\mathrm{k}_{\mathrm{d}}\right)$, determination coefficients $\left(\mathrm{R}^{2}\right)$, and half-life $\left(\mathrm{t}_{1 / 2}\right)$ of the CALB lipase immobilized in xerogel and aerogel with and without the presence of PEG additive.

\begin{tabular}{llll|lll}
\hline & \multicolumn{3}{l|}{ Aerogel without PEG } & \multicolumn{3}{l}{ Aerogel with PEG } \\
\hline Temperature $\left({ }^{\circ} \mathrm{C}\right)$ & $\mathrm{k}_{\mathrm{d}}\left(\mathrm{h}^{-1}\right)$ & $\mathrm{R}^{2}$ & $\mathrm{t}_{1 / 2}(\mathrm{~h})$ & $\mathrm{k}_{\mathrm{d}}\left(\mathrm{h}^{-1}\right)$ & $\mathrm{R}^{2}$ & $\mathrm{t}_{1 / 2}(\mathrm{~h})$ \\
\hline 40 & 0.12 & 0.93 & 6.02 & 0.07 & 0.95 & 9.77 \\
50 & 0.20 & 0.93 & 3.39 & 0.09 & 0.92 & 7.49 \\
60 & 0.32 & 0.96 & 2.17 & 0.22 & 0.93 & 3.19 \\
70 & 0.57 & 0.95 & 1.21 & 0.46 & 0.85 & 1.49 \\
80 & 1.26 & 0.88 & 0.55 & 1.23 & 0.97 & 0.56 \\
\hline \multicolumn{6}{l}{ Xerogel without PEG } & \multicolumn{3}{|l}{ Xerogel with PEG } \\
\hline Temperature $\left({ }^{\circ} \mathrm{C}\right)$ & $\mathrm{k}_{\mathrm{d}}\left(\mathrm{h}^{-1}\right)$ & $\mathrm{R}^{2}$ & $\mathrm{t}_{1 / 2}(\mathrm{~h})$ & \multicolumn{4}{l}{$\mathrm{k}_{\mathrm{d}}\left(\mathrm{h}^{-1}\right)$} & $\mathrm{R}^{2}$ & $\mathrm{t}_{1 / 2}(\mathrm{~h})$ \\
\hline 40 & 0.10 & 0.96 & 6.73 & 0.07 & 0.90 & 9.93 \\
50 & 0.16 & 0.92 & 4.37 & 0.07 & 0.92 & 9.78 \\
60 & 0.22 & 0.92 & 3.22 & 0.09 & 0.86 & 7.78 \\
70 & 0.54 & 0.98 & 1.27 & 0.42 & 0.92 & 1.65 \\
80 & 1.26 & 0.98 & 0.55 & 0.78 & 0.94 & 0.89 \\
\hline
\end{tabular}

Regarding the use of the PEG additive in the immobilization process, it can be observed for the two supports under study (xerogel and aerogel), its presence increased the half-life and reduced the $\mathrm{k}_{\mathrm{d}}$ value. This indicates a positive effect of PEG on the thermal stability of the enzyme. The xerogel showed the greatest increase in half-life (142\%) at a temperature of $60{ }^{\circ} \mathrm{C}$, and the aerogel had the greatest increase $(120 \%)$ at a temperature of $50{ }^{\circ} \mathrm{C}$.

Among the supports, the xerogel demonstrated a better performance in thermal stability at all temperatures. These results may be associated with the presence of more water in the xerogel matrix than in aerogel. This is because the water molecules around the enzyme form a hydration shell and maintain the native conformation of the enzyme [21]. Also, some reports have shown that the native states of proteins could be mostly stabilized by polyols, such as the usual protective additives PEG and glycerol [22]. Because of this, PEG can also be used as a surfactant [23].

The results obtained for these supports with the presence of the additive allow their use in processes that require higher temperatures. Additives must ensure the stability and reuse of the enzyme and, consequently, improve the cost-benefit of the process. The obtained results are important to improve the enzymatic performance and to explore the potential of the application of the enzymes in industrial scales [24]. It should be noted that the additives do not activate the enzyme. Instead, they have a stabilizing effect that prevents the enzyme from being deactivated when interacting with the support.

\section{Conclusions}

In the process of immobilizing the CALB lipase in xerogel and aerogel, the additive PEG showed better performance in AE and stability as an additive when used in the xerogel. This may be due to the process of obtaining the xerogel in which solvent extraction is by evaporation only. When PEG was used as an additive in aerogel, there was a reduction in AE, which may be due to the interaction of PEG with $\mathrm{CO}_{2}$ in the drying process. In conclusion, PEG acts as a good additive in the immobilization process using the sol-gel technique. 


\section{Funding}

This research received no external funding.

\section{Acknowledgments}

\section{The authors thank URI-Erechim, National Council for Scientific and Technological Development $(\mathrm{CNPq})$, Coordination for the Improvement of Higher Education Personnel (CAPES), and Research Support Foundation of the State of Rio Grande do Sul (FAPERGS).}

\section{Conflicts of Interest}

The authors declare no conflict of interest.

\section{References}

1. Martin, L.S.; Cerón, A.A.; Molinari, D.; De Moraes, F.F.; Arroyo, P.A.; De Castro, H.F.; Zanin, G.M. Enhancement of Lipase Transesterification Activity by Immobilization on $\beta$-Cyclodextrin-Based Polymer. J. Sol-Gel Sci. Technol. 2019, 91, 92-100, https://doi.org/10.1007/s10971-019-05011-5.

2. $\quad$ Li, X.; Yang, Z.; Li, K.; Zhao, S.; Fei, Z.; Zhang, Z. A Flexible Silica Aerogel with Good Thermal and Acoustic Insulation Prepared via Water Solvent System. J. Sol-Gel Sci. Technol. 2019, 92, 652-661, https://doi.org/10.1007/s10971-019-05107-y.

3. Larreal de Hernandez, L.; Anez-Borges, L.; Woignier, T.; Hafidi Alaoui, A.; Calas-Etienne, S.; Despetis, F.; Bonnet, L.; Colaiocco, B.; Tahir, S.; Dieudonné-George, P. Surface and Porous Textural Properties of SilicaWollastonite Composites Prepared by Sol-Gel Process. J. Sol-Gel Sci. Technol. 2019, 90, 113-125, https://doi.org/10.1007/s10971-018-4874-9.

4. Pierre, A.C. From Random Glass Networks to Random Silica Gel Networks and Their Use as Host for Biocatalytic Applications. J. Sol-Gel Sci. Technol. 2019, 90, 172-186, https://doi.org/10.1007/s10971-0184798-4.

5. Kovalenko, G.A.; Perminova, L.V.; Krasnikov, D.V.; Kuznetsov, V.L. Macroporous Carbon Aerogel as a Novel Adsorbent for Immobilized Enzymes and a Support for the Lipase-Active Heterogeneous Biocatalysts for Conversion of Triglycerides and Fatty Acids. J. Porous Mater. 2018, 25, 1017-1026, https://doi.org/10.1007/s10934-017-0512-0.

6. Kadotani, S.; Nokami, T.; Itoh, T. Enhanced Activity and Modified Substrate-Favoritism of Burkholderia Cepacia Lipase by the Treatment with a Pyridinium Alkyl-PEG Sulfate Ionic Liquid. Tetrahedron 2019, 75, 441-447, https://doi.org/10.1016/j.tet.2018.12.028.

7. Pazol, J.; Vázquez, A.; Nicolau, E. Characterization of Non-Covalent Immobilized Candida Antartica Lipase b over PS-b-P4VP as a Model Bio-Reactive Porous Interface. Colloids Surfaces B Biointerfaces 2019, 183, https://doi.org/10.1016/j.colsurfb.2019.110418.

8. Ponamoreva, O.N.; Lavrova, D.G.; Kamanina, O.A.; Rybochkin, P.V.; Machulin, A.V.; Alferov, V.A. Biohybrid of Methylotrophic Yeast and Organically Modified Silica Gels from Sol-Gel Chemistry of Tetraethoxysilane and Dimethyldiethoxysilane. J. Sol-Gel Sci. Technol. 2019, 92, 359-366, https://doi.org/10.1007/s10971-019-04967-8.

9. Munim, S.A.; Raza, Z.A. Poly(Lactic Acid) Based Hydrogels: Formation, Characteristics and Biomedical Applications. J. Porous Mater. 2019, 26, 881-901, https://doi.org/10.1007/s10934-018-0687-z.

10. Zakharov, A.G.; Voronova, M.I.; Bazanov, A.V.; Surov, O.V. Porous Composites of Water-Soluble Polymers with Cellulose Nanocrystals. J. Sol-Gel Sci. Technol. 2019, 92, 484-495, https://doi.org/10.1007/s10971-019-05007-1.

11. Çakmakçi, E.; Demir, S. Nonhydrolytic Sol-Gel Synthesized Oligosiloxane Resin Reinforced Thiol-Ene Photocured Coatings for the Immobilization of Acetylcholinesterase. J. Sol-Gel Sci. Technol. 2019, 91, 7281, https://doi.org/10.1007/s10971-019-05006-2.

12. Ficanha, A.M.M.; Nyari, N.L.D.; Levandoski, K.; Mignoni, M.L.; Dallago, R.M. Study of Immobilization of Lipase in Silica by the Sol-Gel Technique. Quim. Nova 2015, 38, 364-369, https://doi.org/10.5935/01004042.20150027.

13. Ficanha, A.M.M.; Antunes, A.; Oro, C.E.D.; Valduga, A.T.; Matuella Moreira, C.; Dallago, R.M.; Mignoni, M. Study of Drying Conditions of the Aerogel Obtained by the Sol-Gel Technique for Immobilization in Situ of Lipase Candida Antarctica B. Ind. Biotechnol. 2019, 15, 350-356, https://doi.org/10.1089/ind.2019.0003.

14. Mohidem, N.A.; Bin Mat, H. Catalytic Activity and Stability of Laccase Entrapped in Sol-Gel Silica with Additives. J. Sol-Gel Sci. Technol. 2012, 61, 96-103, https://doi.org/10.1007/s10971-011-2596-3.

15. Yi, Y.; Neufeld, R.; Kermasha, S. Controlling Sol-Gel Properties Enhancing Entrapped Membrane Protein 
Activity through Doping Additives. J. Sol-Gel Sci. Technol. 2007, 43, 161-170, https://doi.org/10.1007/s10971-007-1562-6.

16. Mandal, C.; Donthula, S.; Rewatkar, P.M.; Sotiriou-Leventis, C.; Leventis, N. Experimental Deconvolution of Depressurization from Capillary Shrinkage during Drying of Silica Wet-Gels with SCF CO2 Why Aerogels Shrink? J. Sol-Gel Sci. Technol. 2019, 92, 662-680, https://doi.org/10.1007/s10971-019-05124-X.

17. Zhang, C.; Liu, Y.; Sun, Y. Lipase Immobilized to a Short Alkyl Chain-Containing Zwitterionic Polymer Grafted on Silica Nanoparticles: Moderate Activation and Significant Increase of Thermal Stability. Biochem. Eng. J. 2019, 146, 124-131, https://doi.org/10.1016/j.bej.2019.03.012.

18. Zhuang, W.; Gu, W.; Zhu, Q.; Zhu, J.; Wang, Z.; Niu, H.; Liu, D.; Wu, J.; Chen, Y.; Li, M.; Zhu, C.; Ying, H. Surface Functionalization of Graphene Oxide by Disodium Guanosine 5'-Monophosphate and Its Excellent Performance for Lipase Immobilization. Appl. Surf. Sci. 2019, 492, 27-36, https://doi.org/10.1016/j.apsusc.2019.05.166.

19. Castejón, N.; Moreno-Pérez, S.; Abreu Silveira, E.; Fernández Lorente, G.; Guisán, J. M.; Señoráns, F. J. Synthesis of Omega-3 Ethyl Esters from Chia Oil Catalyzed by Polyethylene Glycol-Modified Lipases with Improved Stability. Food Chem. 2019, 271, 433-439, https://doi.org/10.1016/j.foodchem.2018.07.215.

20. Zaitsev, S.Y.; Savina, A.A.; Zaitsev, I.S. Biochemical Aspects of Lipase Immobilization at Polysaccharides for Biotechnology. Adv. Colloid Interface Sci. 2019, 272, https://doi.org/10.1016/j.cis.2019.102016.

21. Kajiwara, S.; Komatsu, K.; Yamada, R.; Matsumoto, T.; Yasuda, M.; Ogino, H. Improvement of the Organic Solvent Stability of a Commercial Lipase by Chemical Modification with Dextran. Biochem. Eng. J. 2019, 142, 1-6, https://doi.org/10.1016/j.bej.2018.11.003.

22. Chen, G.; Zhang, Q.; Lu, Q.; Feng, B. Protection Effect of Polyols on Rhizopus Chinensis Lipase Counteracting the Deactivation from High Pressure and High Temperature Treatment. Int. J. Biol. Macromol. 2019, 127, 555-562, https://doi.org/10.1016/j.ijbiomac.2019.01.082.

23. Mathiyalagan, S.; Mandal, B. K. Preparation of Metal Doped Quercetin Nanoparticles, Characterization and Their Stability Study. Lett. Appl. NanoBioScience, 2019, 8 (4), 704-710, https://doi.org/10.33263/LIANBS84.704710.

24. Nian, B.; Cao, C.; Liu, Y. Activation and Stabilization of Candida Antarctica Lipase B in Choline ChlorideGlycerol-Water Binary System via Tailoring the Hydrogen-Bonding Interaction. Int. J. Biol. Macromol. 2019, 136, 1086-1095, https://doi.org/10.1016/j.ijbiomac.2019.06.150. 